\title{
Evaluation of different magnetic resonance imaging contrast materials to be used as dummy markers in image-guided brachytherapy for gynecologic malignancies*
}

Avaliação do uso de diferentes agentes de contraste em ressonância magnética como fontes falsas em planejamentos de braquiterapia guiados por imagem

\section{Camila Pessoa Sales ${ }^{1}$, Heloisa de Andrade Carvalho ${ }^{2}$, Khallil Chaim Taverna ${ }^{3}$, Bruno Fraccini Pastorello ${ }^{4}$, Rodrigo Augusto Rubo ${ }^{5}$, Arthur Felipe Borgonovi ${ }^{6}$, Silvia Radwanski Stuart ${ }^{7}$, Laura Natal Rodrigues ${ }^{1}$}

Sales CP, Canalho HA, Taverna KC, Pastorello BF, Rubo RA, Borgonovi AF, Stuart SR, Rodrigues LN. Evaluation of different magnetic resonance imaging contrast materials to be used as dummy markers in image-guided gynaecological brachytherapy. Radiol Bras. 2016 Mai/Jun;49(3):165-169.

Abstract Objective: To identify a contrast material that could be used as a dummy marker for magnetic resonance imaging.

Materials and Methods: Magnetic resonance images were acquired with six different catheter-filling materials-water, glucose 50\%, saline, olive oil, glycerin, and copper sulfate $\left(\mathrm{CuSO}_{4}\right)$ water solution $(2.08 \mathrm{~g} / \mathrm{L})$-inserted into compatible computed tomography/magnetic resonance imaging ring applicators placed in a phantom made of gelatin and $\mathrm{CuSO}_{4}$. The best contrast media were tested in four patients with the applicators in place.

Results: In T2-weighted sequences, the best contrast was achieved with the $\mathrm{CuSO}_{4}$-filled catheters, followed by saline- and glycerin-filled catheters, which presented poor visualization. In addition (also in T2-weighted sequences), $\mathrm{CuSO}_{4}$ presented better contrast when tested in the phantom than when tested in the patients, in which it provided some contrast but with poor identification of the first dwell position, mainly in the ring.

Conclusion: We found $\mathrm{CuSO}_{4}$ to be the best solution for visualization of the applicator channels, mainly in T2-weighted images in vitro, although the materials tested presented low signal intensity in the images obtained in vivo, as well as poor precision in determining the first dwell position.

Keywords: Imaging, three-dimensional; Brachytherapy/methods; Diagnostic techniques, obstetrical and gynecological; Magnetic resonance imaging/methods; Contrast media.

Resu mo Objetivo: Encontrar um material de contraste que possa ser utilizado como fonte falsa em imagens de ressonância magnética.

Materiais e Métodos: Foram feitas imagens de ressonância magnética de cateteres preenchidos com seis meios de contraste conhecidos: água, glicose $50 \%$, soro fisiológico, óleo de oliva, glicerina, solução aquosa de sulfato de cobre $\left(\mathrm{CuSO}_{4}\right)(2.08$ g/L), inseridos em aplicadores de sonda e anel compatíveis com tomografia computadorizada/ressonância magnética colocados em um objeto simulador de gelatina e $\mathrm{CuSO}_{4}$. Os materiais com melhores respostas foram testados em quatro pacientes que utilizaram os aplicadores.

Resultados: Os cateteres preenchidos por $\mathrm{CuSO}_{4}$ apresentaram melhor visualização em sequências T2, seguidos pelos cateteres com solução de soro fisiológico e glicerina, que apresentaram visualização insatisfatória. $\mathrm{O} \mathrm{CuSO}_{4}$ apresentou bom contraste em sequências T2 quando testado em objeto simulador e em pacientes, porém com uma identificação insatisfatória da primeira posição de parada possível para fonte, principalmente no anel.

Conclusão: $\mathrm{O} \mathrm{CuSO}_{4}$ se mostrou a melhor solução para visualização dos canais dos aplicadores, principalmente em sequências T2 in vitro, mas os materiais testados apresentaram baixo sinal nas imagens de ressonância magnética in vivo e uma precisão insatisfatória para identificação da primeira parada de fonte possível.

Unitermos: Imagem tridimensional; Braquiterapia/métodos; Técnicas de diagnóstico obstétrico e ginecológico; Imagem por ressonância magnética/métodos; Meios de contraste.

* Study conducted in the Radiotherapy Department, Hospital das Clínicas da Faculdade de Medicina da Universidade de São Paulo (HC-FMUSP), São Paulo, SP, Brazil.

1. PhD, Medical Physicist, Radiotherapy Department, Instituto de Radiologia do Hospital das Clínicas da Faculdade de Medicina da Universidade de São Paulo (InRad/ HC-FMUSP), São Paulo, SP, Brazil.

2. PhD, Medical Coordinator of the Radiotherapy Department, Instituto de Radiologia do Hospital das Clínicas da Faculdade de Medicina da Universidade de São Paulo (InRad/HC-FMUSP), São Paulo, SP, Brazil.

3. MSc, Medical Physicist, LIM/44 - Laboratório de Ressonância Magnética em Neurorradiologia, Department of Radiology and Oncology, Faculdade de Medicina da Universidade de São Paulo (FMUSP), São Paulo, SP, Brazil.

4. PhD, Medical Physicist, LIM/44 - Laboratório de Ressonância Magnética em
Neurorradiologia, Department of Radiology and Oncology, Faculdade de Medicina da Universidade de São Paulo (FMUSP), São Paulo, SP, Brazil.

5. MSc, Medical Physicist, Radiotherapy Department, Instituto de Radiologia do Hospital das Clínicas da Faculdade de Medicina da Universidade de São Paulo (InRad/ HC-FMUSP), São Paulo, SP, Brazil.

6. BA, Medical Physicist at Royal Philips Electronics, Eindhoven, the Netherlands.

7. MD, Physician in the Division of Radiotherapy, Department of Radiology and Oncology, Faculdade de Medicina da Universidade de São Paulo (FMUSP), São Paulo, SP, Brazil.

Mailing address: Dra. Camila Pessoa Sales. Rua Doutor Ovídio Pires de Campos, 75, Instituto de Radiologia, $3^{\circ}$ andar, Cerqueira César. São Paulo, SP, Brazil, 05403010. E-mail: camyps@gmail.com.

Received January 8, 2015. Accepted after revision July 14, 2015. 


\section{INTRODUCTION}

The major challenge in radiation therapy is to treat lesions with a high effective dose, while minimizing the dose to adjacent normal tissue and organs at risk ${ }^{(1)}$, thus diminishing side effects and treatment complications. To achieve that goal, new technologies have been developed for treatment planning and dose delivery, including three-dimensional (3D) radiotherapy, intensity-modulated radiotherapy, tomotherapy and rapid arc techniques ${ }^{(2-4)}$. Because of its high dose-gradient characteristic, brachytherapy has the potential to help radiation oncologists achieve a good therapeutic ratio (a high dose to the tumor with good preservation of the surrounding normal tissue). In cancer of the uterine cervix, which is one of the most common forms of cancer among women worldwide, brachytherapy plays a major role in local control and patient survival ${ }^{(5)}$. Image-guided or 3D brachytherapy for gynecologic malignancies has the potential to improve local control and survival even further among cervical cancer patients ${ }^{(6,7)}$. However, such techniques are still not in routine use, even in developed countries ${ }^{(8,9)}$.

For 3D brachytherapy planning, it is necessary to conduct image studies that allow volumetric reconstruction of the tumor (or target) and organs at risk. In general, computed tomography (CT) is the method of choice. However, for gynecologic tumors, magnetic resonance imaging (MRI) is the best method to assess the primary tumor volume. Various groups have been studying the use of CT or MRI for 3D brachytherapy planning ${ }^{(6-10)}$, in order to treat the appropriate target volume and quantify the dose delivered to the organs at risk (rectum and bladder), with promising results.

High-dose-rate brachytherapy 3D planning requires applicator reconstruction, which is primarily based on the first dwell position of the source, and should be as precise as possible. For this purpose, dummy seeds are usually placed inside the applicators during image acquisition. The metallic dummies supplied by the manufacturers are CTcompatible but are not MRI-compatible. Since tumor visualization on CT images is limited, implementation of a complete 3D treatment strategy involving delineation of the tumor volume (MRI-based) and of the volume of the organs at risk (MRI- or CT-based) is still a challenge in current practice.

The purpose of this study was to evaluate materials that may be used as contrast media for MRI and verify if they can be used as dummy markers for gynecologic 3D brachytherapy planning.

\section{MATERIALS AND METHODS}

Six capillary catheters were manually filled with six different solutions to be tested: water, glucose $50 \%$, saline, glycerin, olive oil, and a copper sulfate $\left(\mathrm{CuSO}_{4}\right)$ water solution $(2.08 \mathrm{~g} / \mathrm{L})^{(11)}$, and their extremities were sealed with wax. A phantom composed of gelatin and $\mathrm{CuSO}_{4}{ }^{(11)}$ was constructed specifically for image acquisition. As depicted in Figure 1, CT-/MRI-compatible ring applicators (Nucletron/

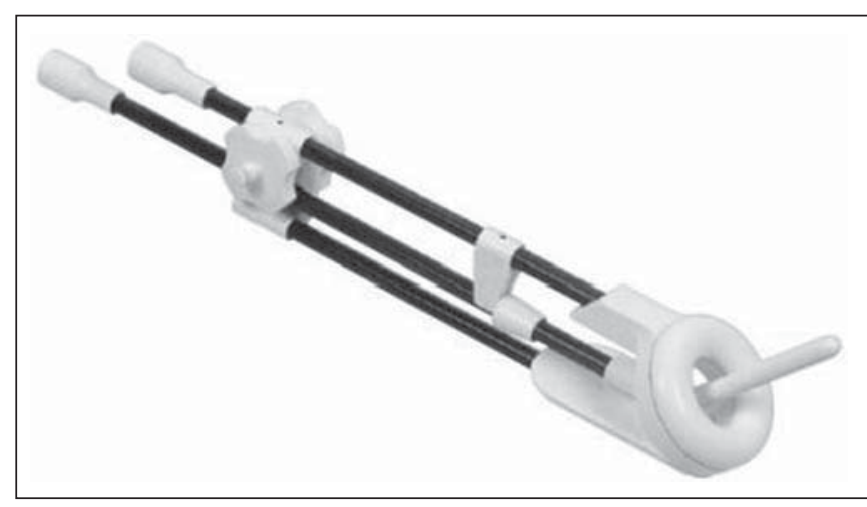

Figure 1. CT-/MRI-compatible ring applicator for gynecologic malignancies.

Elekta AB, Stockholm, Sweden) were placed in the gelatin and the catheters were inserted in the applicators.

To determine which solution and image acquisition technique would provide better visualization of the applicator lumen, T2-weighted images were acquired with variation of the acquisition parameters in a $3 \mathrm{~T}$ scanner (Achieva; Philips Healthcare, Eindhoven, the Netherlands) and in a 1.5 T scanner (Signa HDxt; GE Healthcare, Chalfont St. Giles, UK) scanners. The $1.5 \mathrm{~T}$ scanner is the default equipment for patient imaging. The acquisition parameters were sequence type, echo time (TE), repetition time (TR), slice spacing, and slice thickness (Table 1). The slices were aligned following the tandem axis, parallel to the ring, according to the applicator geometry. Despite the possibility of obtaining good contrast on T1-weighted sequences with gadolinium, the tests were conducted only on T2-weighted sequences, because this is the standard for delineation of gynecologic tumors ${ }^{(12)}$.

A brachytherapy treatment planning system (Oncentra Master Plan; Elekta AB, Stockholm, Sweden) was used in order to analyze the images visually. The best sequence to visualize the dummies was determined through qualitative analysis of the images, and the process was performed by two observers in order to minimize its variability. Subsequently, the solutions that, in a qualitative analysis, presented the best contrast in the phantom were tested in four patients in whom 1.5 T MRI was performed with the brachytherapy applicators in place. The study was approved by the local institutional review board and research ethics committee.

Table 1-Parameters used in MRI sequences.

\begin{tabular}{ccccccc}
\hline & & & \multicolumn{2}{c}{ Slice } & & \\
\cline { 4 - 5 } Series & Orientation & Sequence & $\begin{array}{c}\text { Spacing } \\
(\mathrm{mm})\end{array}$ & $\begin{array}{c}\text { Thickness } \\
(\mathrm{mm})\end{array}$ & $\begin{array}{c}\text { TR } \\
(\mathrm{ms})\end{array}$ & $\begin{array}{c}\text { TE } \\
(\mathrm{ms})\end{array}$ \\
\hline 1 & Coronal & T2 Cube & 1.3 & 1.3 & 1500 & 140 \\
2 & Axial & T2 Cube & 1.3 & 1.3 & 1500 & 140 \\
3 & Oblique & T2 Cube & 1.3 & 1.3 & 1500 & 140 \\
4 & Axial & T2 FSE & 0.5 & 3.0 & 5083 & 140 \\
5 & Axial & T2 FSE & 1.0 & 3.0 & 7000 & 140 \\
6 & Axial & T2 FSE & 1.5 & 1.5 & 9000 & 140 \\
\hline
\end{tabular}

FSE, fast spin-echo. 


\section{RESULTS}

The images were compared in order to determine which solution and MRI sequence promoted the best visualization for applicator reconstruction (Figures 2 and 3). In T2weighted sequences, the $\mathrm{CuSO}_{4}$ solution presented the highest contrast (Figure 3), followed by glycerin and saline, both of which presented poor contrast (Figure 2). Comparing these solutions, $\mathrm{CuSO}_{4}$ presented a better contrast than saline and glycerin. The best combination was an axial T2-weighted fast spin-echo cube sequence —slice spacing $=1.3 \mathrm{~mm}$, slice thickness $=1.3 \mathrm{~mm}, \mathrm{TR}=1500 \mathrm{~ms}$, and TE $=140 \mathrm{~ms}$ (Table 1$)$ used in order to visualize the $\mathrm{CuSO}_{4}$ solution (Figure 4). Efforts to place a specific slice as the most coincident with the dummy in the ring had to be made in order to achieve better visualization of the dummy. When tested in patients, $\mathrm{CuSO}_{4}$ presented some contrast in T2-weighted sequences (Figure 5). Although $\mathrm{CuSO}_{4}$ could be visualized in the MRI

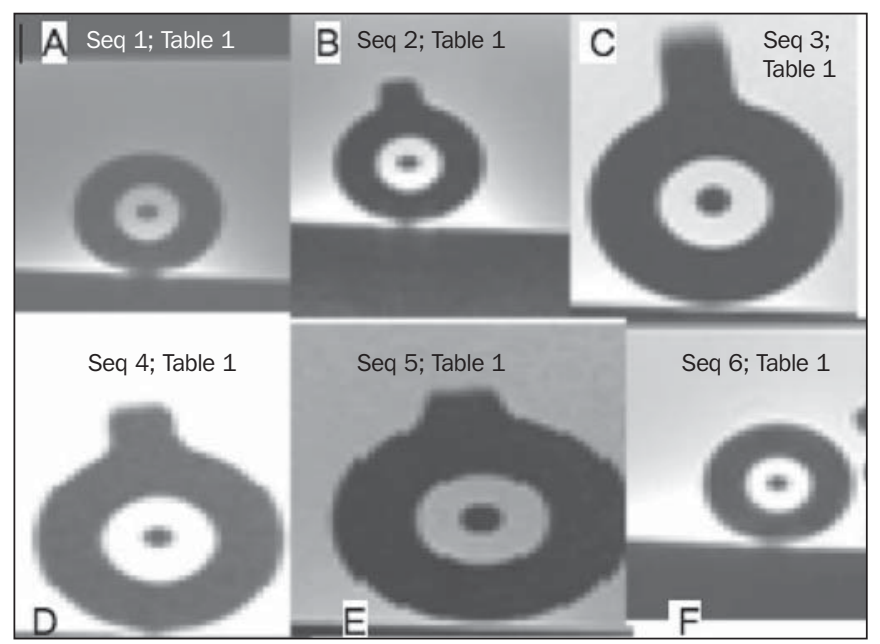

Figure 2. MRI scan (T2-weighted sequence) in which the glycerin ring lumen and saline tandem lumen solutions were tested as dummies. The figures show the various acquisitions (detailed in Table 1 ) for each solution.

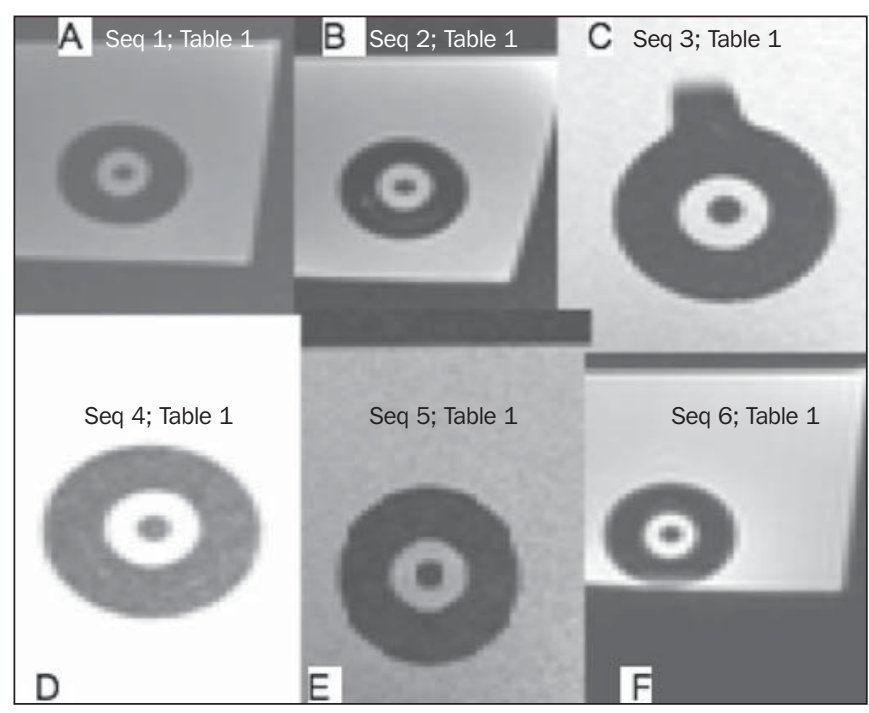

Figure 3. MRI scan (T2-weighted sequence) in which the $\mathrm{CuSO}_{4}$, ring lumen and tandem lumen solutions were tested as dummies. The figures show the various acquisitions (detailed in Table 1) for each solution.

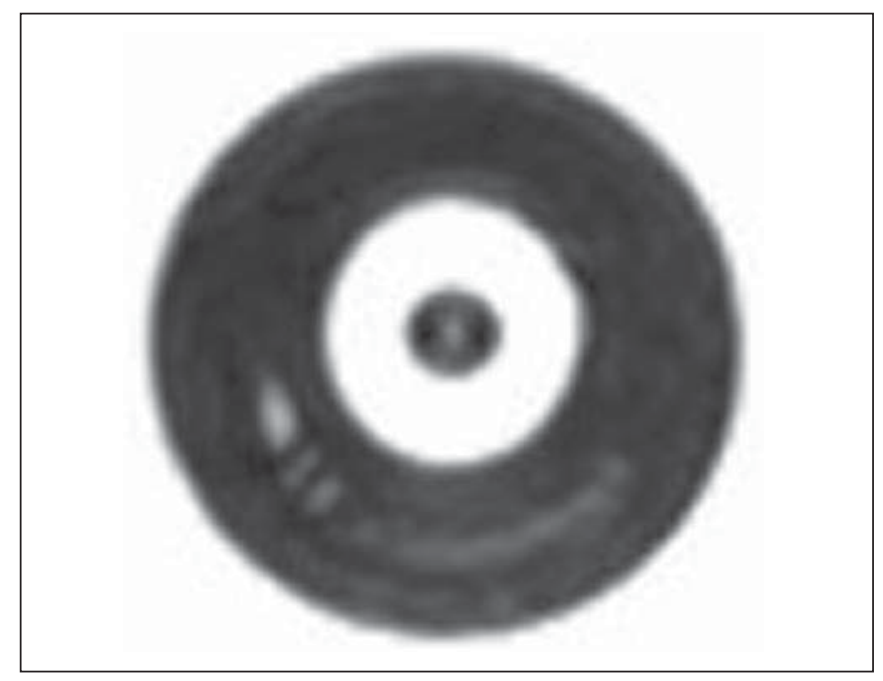

Figure 4. MRI scan (T2-weighted sequence) in which the $\mathrm{CuSO}_{4}$ dummy is visualized in the ring lumen.

sequences obtained in the patients (Figure 5), the resolution was not sufficient to determine the first dwell position, mainly in the ring.

\section{DISCUSSION}

Image-guided brachytherapy for gynecologic malignancies can be performed with CT or MRI scans. However, T2weighted MRI is the gold standard for defining the tumor volume in patients with cancer of the uterine cervix ${ }^{(12)}$. When the procedure is performed exclusively on the basis of CT scans, tumor coverage is not evaluated appropriately. Nevertheless, applicator reconstruction is a key point for a precise and definitive calculation, and manufacturers do not provide MRI-compatible dummies for all kinds of applicators. One option to solve this problem is CT-MRI image fusion, although that leads to uncertainties due to image distortions that may be unacceptable, mainly in brachytherapy. In addition, the need to perform two image studies for the same procedure raises the costs, which cannot be neglected. Therefore, applicator reconstruction in MRI scans, where the target volume is best visualized, is mandatory for complete $3 \mathrm{D}$ treatment.

The $\mathrm{CuSO}_{4}$ solution provided a good signal, with an acceptable, albeit poor, applicator reconstruction, mainly due to the difficulty in identifying the ends of the catheters. The wax material used to seal the catheter tips does not provide good MRI contrast. In addition, because the catheters are very thin, high precision is needed in order to seal the tips with an exact, known amount of wax, which was not achieved in this experiment. Haack et al. ${ }^{(11)}$ reported that $\mathrm{CuSO}_{4}$ provides a degree of MRI contrast better than that demonstrated in our study. Because those authors used applicators from a different manufacturer, it is likely that the difference between the two types of applicators, in terms of the caliber of the channels (Nucletron applicators have a narrower lumen) could explain the lower contrast that we observed. All of the other materials tested in our study also presented low signal 


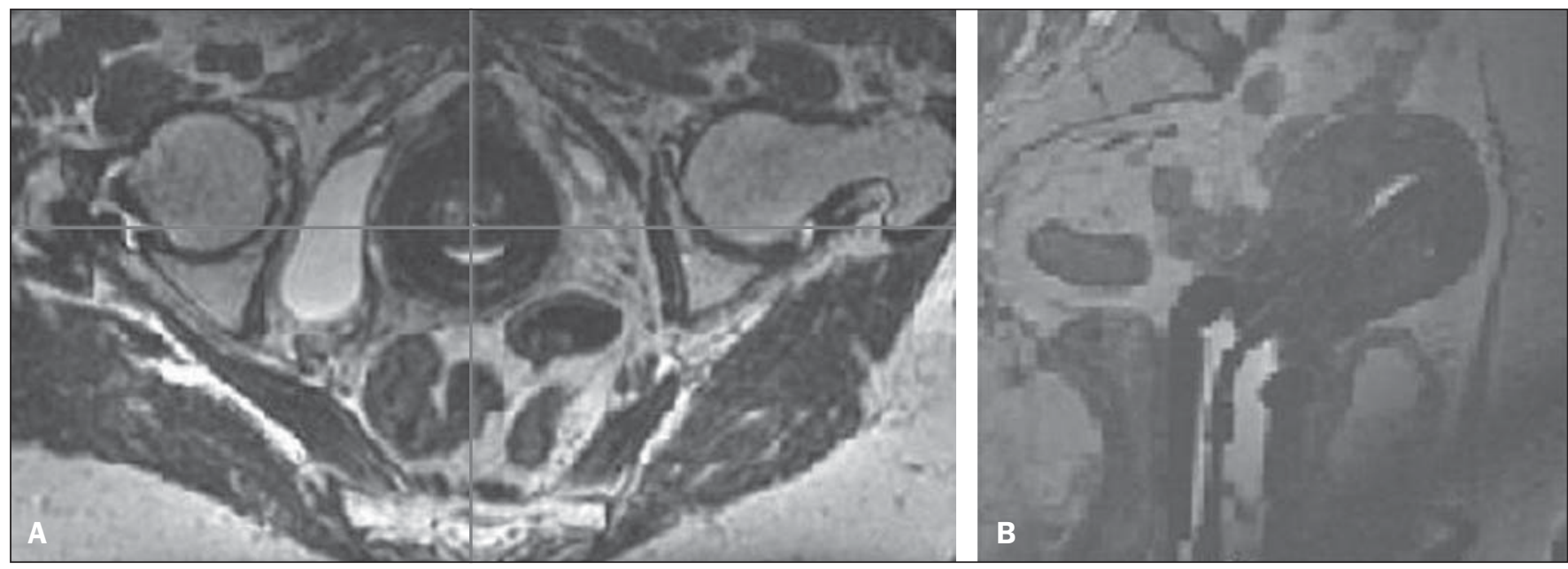

Figure 5. MRI scan (T2-weighted sequence) of one patient with the applicators in place and the $\mathrm{CuSO}_{4}$ dummies. A: Axial section: ring. B: Sagittal section: tandem.

intensity in the MRI scans. This was, once again, probably due to the very narrow applicator lumen, allowing only a capillary-like catheter to be inserted, with a very low volume of contrast. Recently, the manufacturer developed a new applicator with a larger lumen, which could improve the visualization of contrast inside larger catheters, although only a few hospitals in developing countries can afford to purchase this new applicator.

Only three of the six solutions tested were visible in the T2-weighted images generated using the phantom, and only one allowed satisfactory visualization. However, when used in the patients, the contrast was insufficient to reconstruct the applicators appropriately. The differences found between the images generated using the phantom and those acquired in the patients were probably due to the variety of signals generated by the patients themselves, which can make it difficult to identify low-intensity signals like those emanating from very thin catheters.

As an alternative to solve the problem of applicator reconstruction, a radiograph of the rings with the dummies provided by the manufacturer (that are only CT-compatible) may be printed in a transparency ${ }^{(13)}$. This is superimposed to the ring in an MRI scan in the same projection as the Xray. For the tandem, the procedure is much easier, since the distance from the first dwell position to the tandem tip is already known, which allows a very reliable reconstruction to be performed.

The best alternative for applicator reconstruction is the "applicator library" provided by the manufacturer for tandem and ring applicators ${ }^{(14)}$. With this tool, it is possible to estimate the location of the first dwell position. The precise determination of this location is not mandatory when using the library, because it is possible to match the entire applicator library with the MRI applicator.

A valid option for evaluating the precision of the reconstruction is to determine the distance from the tip of the tandem and the ring to the first dwell position, as an initial reference point for reconstruction in the images. This also can be a challenge, mainly in relation to the ring, because this reference should be based in the acquired images. In order to evaluate the reliability of the applicator reconstruction, it is recommended that the fixed applicator distances and angles determined previously be compared with those measured in $\mathrm{MRI}^{(11)}$. The parameters of interest are the distance between the first dwell position in the tandem and the ring, together with the angle between this distance and the applicator origin, in the coronal section (Figure 6), as well as the distance between the first dwell position in the ring and the applicator origin, together with the angle between this distance and the axis perpendicular to the rectal retractor, in the axial section when the image is aligned with the rectal retractor to verify the ring rotation (Figure 7).

Comparing the different contrast solutions, we were able to identify the best contrast media to be used in MRI. However, with the applicator studied, the results were not satisfactory. The contrast solution may be an option to be used in other situations in which determination of the first dwell position is mandatory, as when different types of applicators, such as those with a larger lumen, are used.

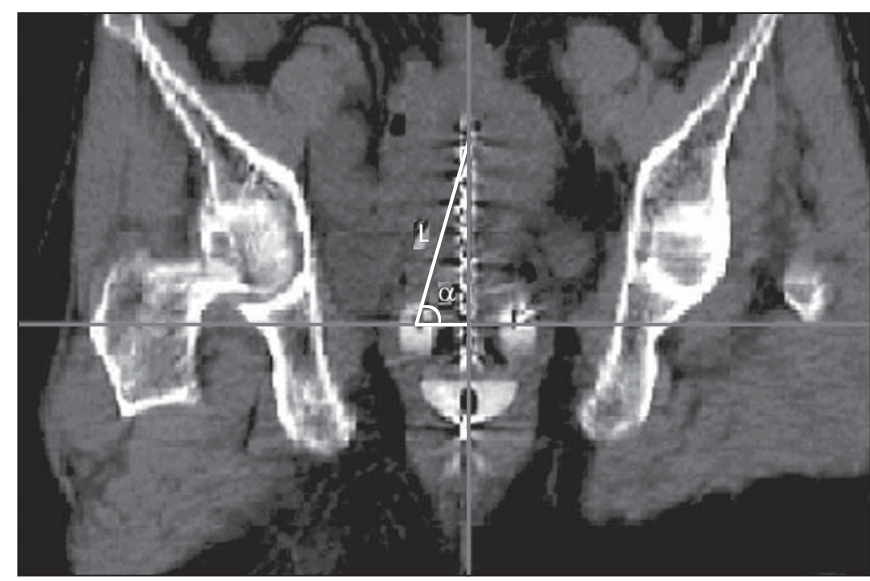

Figure 6. Coronal section showing the distance between the first dwell position in the tandem and the ring $(\mathrm{L})$, as well as the angle $(\alpha)$ between this distance and the applicator origin . 
Figure 7. Axial section image showing the distance (L) between the first dwell position in the ring and the applicator origin, as well as the angle $(\alpha)$ between this distance and the axis perpendicular to the recta retractor, when the image is aligned with the rectal retractor in this plane, to verify the ring rotation.

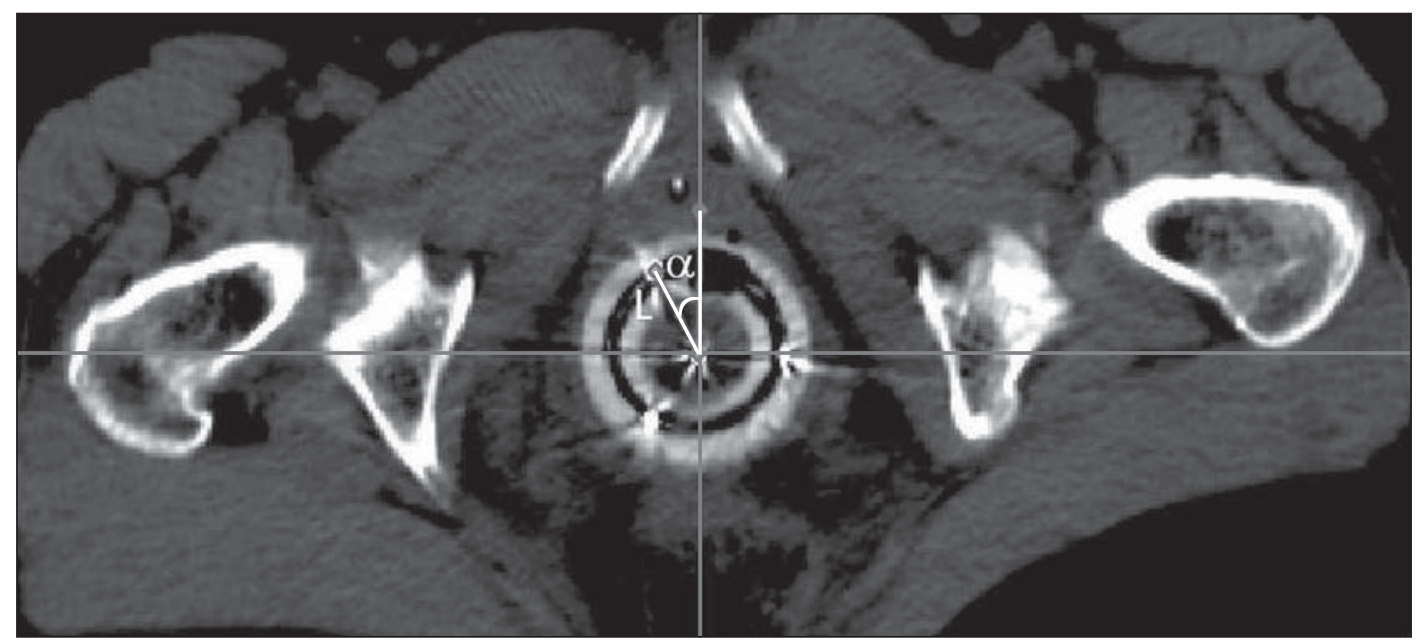

\section{CONCLUSIONS}

We found $\mathrm{CuSO}_{4}$ to be the best solution for in vitro visualization of the applicator channels, mainly in T2weighted images. However, the materials tested presented low signal intensity in the in vivo images and poor precision in determining the first dwell position, thus precluding appropriate reconstruction, since the applicators studied have a very narrow channel diameter and the dummy manufacturing process used was not suitable. For clinical purposes, it is necessary to use the library of applicators to guarantee an accurate reconstruction.

\section{REFERENCES}

1. International Commission on Radiological Units. Prescribing, recording and reporting photon beam therapy (Supplement to ICRU Report 50). ICRU Report 62. Bethesda, MD; 1999.

2. Ji YS, Dong KR, Kim CB, et al. Comparison of dose-volume histograms for tomotherapy, linear accelerator-based 3D conformal radiation therapy, and intensity-modulated radiation therapy. Annals of Nuclear Energy. 2011;38:2569-74.

3. Vieillot S, Azria D, Lemanski C, et al. Plan comparison of volumetric-modulated arc therapy (RapidArc) and conventional intensitymodulated radiation therapy (IMRT) in anal canal cancer. Radiat Oncol. 2010;5:92.

4. Alvarez-Moret J, Pohl F, Koelbl O, et al. Evaluation of volumetric modulated arc therapy (VMAT) with Oncentra MasterPlan ${ }^{\circledR}$ for the treatment of head and neck cancer. Radiat Oncol. 2010;5:110.

5. Jemal A, Bray F, Center MM, et al. Global cancer statistics. CA Cancer J Clin. 2011;61:69-90.

6. Pötter R, Dimopoulos J, Georg P, et al. Clinical impact of MRI assisted dose volume adaptation and dose escalation in brachytherapy of locally advanced cervix cancer. Radiother Oncol. 2007;83:14855.

7. Pötter R, Georg P, Dimopoulos JC, et al. Clinical outcome of protocol based image (MRI) guided adaptive brachytherapy combined with 3D conformal radiotherapy with or without chemotherapy in patients with locally advanced cervical cancer. Radiother Oncol. 2011;100:116-23.

8. Viswanathan AN, Erickson BA. Three-dimensional imaging in gynaecologic brachytherapy: a survey of the American Brachytherapy Society. Int J Radiat Oncol Biol Phys. 2010;76:104-9.

9. Pavamani S, D'Souza DP, Portelance L, et al. Image-guided brachytherapy for cervical cancer: a Canadian Brachytherapy Group survey. Brachytherapy. 2011;10:345-51.

10. Wang B, Kwon A, Zhu Y, et al. Image-guided intracavitary highdose-rate brachytherapy for cervix cancer: a single institutional experience with three-dimensional CT-based planning. Brachytherapy. 2009;8:240-7.

11. Haack S, Nielsen SK, Lindegaard JC, et al. Applicator reconstruction in MRI 3D image-based dose planning of brachytherapy for cervical cancer. Radiother Oncol. 2009;91:187-93.

12. Pötter R, Lindegaard J, Kirisits C, et al. A European study in MRIguided brachytherapy in locally advanced cervical cancer - EMBRACE. Version 17-01-2008. [cited 2013 Dec 5]. Available from: https://www.embracestudy.dk/UserUpload/PublicDocuments/ EmbraceProtocol.pdf.

13. Berger D, Dimopoulos J, Pötter R, et al. Direct reconstruction of the Vienna applicator on MR images. Radiother Oncol. 2009;93: 347-51.

14. Tanderup K, Hudej R, Lowe G, et al. Applicator reconstruction in cervix brachytherapy. [cited 2013 Dec 5]. Available from: https:// www.embracestudy.dk/UserUpload/PublicDocuments/ Applicator\%20reconstruction\%20catalogue.PDF. 